\title{
ERRATUM
}

\section{Erratum to: Molecular diversity of Enteromorpha from the coast of Yantai: a dual-marker assessment*}

\author{
LIU Haiyan (刘海燕) $)^{1,2}$, LIU Zhengyi (刘正一) ${ }^{3}$, WANG Yinchu (王寅初) ${ }^{1,2}$, \\ ZHAO Yushan (赵玉山) $)^{4}$, QIN Song (秦松) $)^{1,2, *}$ \\ ${ }^{I}$ University of Chinese Academy of Sciences, Beijing 100049, China \\ ${ }^{2}$ Yantai Institute of Coastal Zone, Chinese Academy of Sciences, Yantai 264003, China \\ ${ }^{3}$ Key Lab of Marine Biology in Jiangsu, College of Resources and Environmental Sciences, Nanjing Agricultural University, \\ Nanjing 210095, China \\ ${ }^{4}$ Shandong Oriental Ocean Sci-Tech Co. Ltd., Yantai 264003, China \\ (C) Chinese Society for Oceanology and Limnology, Science Press, and Springer-Verlag Berlin Heidelberg 2014
}

Erratum to: Chinese Journal of Oceanology and Limnology

Vol. 31 No. 6, P. 1210-1215, 2013

http://dx.doi.org/10.1007/s00343-013-3045-7

The supporting grant information on the footnote of the original version of this article needs to be altered and updated. The new information is given below.

* Supported by the National Key Technology Research and Development Program of China (No. 2013BAB01B01)

The online version of the original article can be found at http://dx.doi.org/10.1007/s00343-013-3045-7. 